\title{
Analyzing the Trend and Clustering of Groundwater Measuring Sites in Nadia and Burdwan Districts of West Bengal
}

\author{
P.K. Sahu*, Vishwajith K.P., B.S. Dhekale and P. Mishra \\ Department of Agricultural Statistics, Bidhan Chandra Krishi Viswavidyalaya, Mohanpur, Nadia 741252, West Bengal
}

\begin{abstract}
Agriculture is the back bone of Indian economy; a substantial percent of GDP is still being contributed by agriculture. For the development of agriculture, assured supply of irrigation is needed. Groundwater plays an important role, not only in mitigating the problem of irrigation water for agriculture but also serves as source for domestic and industrial supply of water. As such fluctuations of groundwater table over the different periods of the year plays important role. In this paper, an attempt has been made to model the groundwater table in two agriculturally important districts namely Nadia and Burdwan. Time series data (2005 to 2013) recorded during January, May, August and November each year from a number of sites in each districts are used for study purpose. Various parametric model are used to delineate and model the fluctuations of groundwater tables for these two districts. Multivariate clustering technique using squared Euclidean distance measure and adopting complete linkage method has been used to cluster 50 sites in Burdwan and 19 sites in Nadia district based on their groundwater fluctuations over the seasons. Analysis reveals that in both the districts three groups could be framed out of the 50 and 19 groundwater level measuring sites of Burdwan and Nadia, respectively. Discriminant analysis was also attempted to identify the contribution of different seasons in groundwater fluctuations during the clustering of the sites in each district. The authors are hopeful that the result of the study will help the planners in taking cluster wise action plan for monitoring and maintaining the groundwater table in these two districts.
\end{abstract}

Key words: Seasonal fluctuation, trend analysis, clustering and discrimination.

\section{Introduction}

Till today about $13.7 \%$ (2012-2013) of the Indian GDP is contributed by agriculture sector [1]. Marginal improvement in Indian GDP during 2013-2014, 4.7\% from $4.5 \%$ in $2012-2013$ is also substantial contribution by agriculture and allied sector, which grew at $4.7 \%$ compared to their long run average of $3 \%$ during 1999-2000 and 2012-2013, mainly attributed to favorable rainfall [2]. For the development of agriculture, assured supply of irrigation is needed. Groundwater plays an important role, not only in mitigating the problem of irrigation water for agriculture, but also serves as source for domestic and industrial supply of water.

Corresponding author: Pradip Kumar Sahu, Ph.D., research fields: statistics, agricultural statistics, econometrics, modeling and forecasting. E-mail: pksbckv@gmail.com.
A comparison of depth of water level between May, August, November in 2011 and that of 2010 reveals that in general there is decline, rise, respectively, rise of water table within range of $0-2 \mathrm{~m}$ [3]. Water requirement for various sector in West Bengal was estimated to be 13.02 Mham for 2011 which is less than supply by 48 percent [4] which affects the per capita water availability of $720 \mathrm{~m}^{3}$ during 2011. Also groundwater development in West Bengal is just 40 percent in 2011-2012 [3]. As such fluctuations of groundwater table over the different periods of the year plays important role. An attempt has been made to model the groundwater table in two agriculturally important districts namely Nadia and Burdwan.

Nadia is geographically surrounded by Republic of Bangladesh in the East, Burdwan and Hugli district on the West, Murshidabad district on the North and North West and North 24 Parganas towards South and South 
East. Nadia covers 391 thousand hectare geographical area covering a gross irrigation of 217.9 in thousand hectare. The economy of Nadia mostly depends on agriculture where most important agricultural crops like paddy and jute and horticultural crops like mango, papaya, lichi, tomato, ginger, garlic, flowers and other vegetables are grown and also various handicrafts can also be seen in the district. The per capita water availability in Nadia was 415.8 cum/capita (according to 2001 census) which is categorized under sever water scarcity area [5].

Burdwan is another district under present study bounded geographically by districts- Dumka of Jharkhand, Birbhum and Murshidabad on North, on the East by Nadia, South by Hooghly, Bankura and Purulia and on the West by Dhanbad of Jharkhand. Burdwan covers 698.8 thousand hectare geographical area, out of which 458.51 thousand hectare is under cultivation. The figure of area under irrigation 331.65 (72.33\% of cultivated land) thousand hectare clearly indicate the dependency of agriculture on groundwater. The district receives normal annual rainfall of 1,440.9 mm. Major agricultural and horticultural crops grown are rice, jute, oilseeds, wheat and potato. Both the districts are strong with reference to trade and commerce. The per capita water availability in Burdwan was 757.02 cum/capita (according to 2001 census) which is categorized under water scarcity area [4].

The increasing population of these two districts leading them to depend more on groundwater for domestic, agricultural and various other purposes. As such fluctuation of ground water table and its study is important from social, economic and livelihood point of view for these two districts. The authors are hopeful that the result of the study will help the planners in taking cluster wise action plan for monitoring and maintaining the groundwater table in these two districts.

\section{Methodology}

Poor or scarcity in site wise availability of consistent data on groundwater is the main problem in time series analysis on such parameters. The present study has been under taken with the help of site wise groundwater level data on seasonal basis (i.e January, May, August and November) available at http://gis2.nic.in/cgwb/Gemsdata.aspx for the period 2005 to 2013 in two districts viz. Nadia and Burdwan of West Bengal.

Descriptive statistics which includes numerical and graphical statistical measure like minimum, maximum, average, standard error, skewness, kurtosis, simple growth rate are useful to describe the patterns and general behavior of a data set were used in this study. Various parametric model are used to delineate and model the fluctuations of groundwater tables for these two districts. Multivariate clustering technique using squared Euclidean distance measure and adopting complete linkage method has been used to cluster 50 sites in Burdwan and 19 sites in Nadia district based on their groundwater fluctuations over the seasons.

To get an idea about the overall movement of the time series data, trend equations are fitted. In this exercise different models like linear $\left(\mathrm{Y}_{\mathrm{t}}=\mathrm{b}_{0}+\mathrm{b}_{1} \mathrm{t}\right)$, polynomial $\left(\mathrm{Y}_{\mathrm{t}}=\mathrm{b}_{0}+\mathrm{b}_{1} \mathrm{t}+\mathrm{b}_{2} \mathrm{t}^{2}+\mathrm{b}_{2} \mathrm{t}^{3}+\ldots \ldots \ldots \ldots+\right.$ $\left.b_{k} t^{k}\right)$, exponential $\left(Y_{t}=b_{0} e^{(b 1 t)}\right)$, regression with dummy variables etc. are used for the purpose.

Regression with dummy variable:

$\mathrm{Y}=\beta_{0}+\beta_{1} D_{1}+\beta_{2} D_{2}+\beta_{3} D_{3}+e$

$D_{1}=1$, if the month is January, $=0$, otherwise;

$D_{2}=1$, if the month is May, $=0$, otherwise;

$D_{3}=1$, if the month is August, $=0$, otherwise;

$\mathrm{E}\left(\mathrm{Y} / D_{1}=1, D_{2}=0, D_{3}=0\right.$,

= Average groundwater table during January;

$\mathrm{E}\left(\mathrm{Y} / D_{2}=1, D_{1}=0, D_{3}=0\right.$,

= Average groundwater table during May;

$\mathrm{E}\left(\mathrm{Y} / D_{3}=1, D_{1}=0, D_{2}=0,\right)$

$=$ Average groundwater table during August.

Based on significance of coefficient and minimum value of RMSE and maximum $\mathrm{R}^{2}$ value, the best model is selected.

Cluster analysis is a multivariate statistical analysis 
technique used for wide variety of research approaches and here it is used to group the sites/villages into clusters such that each cluster is as homogeneous as possible with respect to groundwater table values. Here, no assumptions are made regarding the number of clusters/groups and the group membership and it is done on the basis of similarities or dissimilarities (distances). A hierarchical clustering creates a hierarchical decomposition of data elements in the form of tree like diagram called Dendogram, which look like tree of set of nested clusters. There are two approaches to build a cluster hierarchy: one is Agglomerative method: A Bottom-up approach, i.e., from single whole cluster to clusters of single elements, and the other is Divisive method: Top-down approach, i.e., from single element cluster to group of elements as cluster. Tree clustering method uses the dissimilarities or distances between objects in the process of forming the clusters. In the present study, complete linkage is used for computing the distance between clusters and it works on the principle of distant neighbour or dissimilarities-farthest neighbour. The maximum distance between elements of each clusters is given by:

$$
\max \{d(x, y): x \in A, y \in B\}
$$

Euclidean distance between two data points involves computing the square root of the sum of the squares of the differences between corresponding values. $\mathrm{X}$ and $\mathrm{Y}$ are two elements measured for $i=(1,2, \ldots, \mathrm{n})$ characters, then Euclidean distance between $\mathrm{X}$ and $\mathrm{Y}$ is given as:

$$
d=\sqrt{\sum_{i=1}^{n}\left(X_{i}-y_{i}\right)^{2}}
$$

In the present study, Squared Euclidean distance is used between sites involves computing the sum of the squares of the differences between corresponding values, which gives progressively greater weightage to objects which are far apart from each other. Squared Euclidean distance is frequently used in optimization problems where distances are only compared. The formula for this distance between sites $\mathrm{X}$ and $\mathrm{Y}$ measured for $i=(1,2, \ldots, \mathrm{n})$ characters is given by:

$$
d=\sum_{i=1}^{n}\left(\boldsymbol{X}_{i}-y_{i}\right)^{2}
$$

One way ANOVA is carried out to verify the hypothesis that, groundwater level in various cluster formed in different seasons are same, i.e.,

$$
H_{0}: \mu_{1}=\mu_{2}=\ldots .=\mu_{k} \quad(k=1,2, \ldots . .)
$$

Against, $H_{1}=$ All clusters are not equal.

Discriminant analysis was also attempted to identify the contribution of different seasons in groundwater fluctuations during the clustering of the sites in each district. Discriminant analysis is a statistical technique, used to study the differences between two or more groups of objects with respect to several variables simultaneously. DFA (Discriminant Function Analysis) is essentially a multiple regression where the dependent variable $\mathrm{Y}$ is a categorical variable, which is used to determine relative contributions of the variables to discriminate among $\mathrm{K}$ groups.

Suppose we have an observation $X_{0}$. Then, based on the discriminant function $l(X)=\hat{a}^{t} X$ developed, one can allocate this observation to some class.

Allocate $X_{0}$ to population 1 if:

$$
\begin{aligned}
& \hat{Y}_{0}=\hat{a}^{t} X_{0}=\left(\bar{X}_{1}-\bar{X}_{2}\right)^{t} S_{\text {pooled }}^{-1} X_{0} \geq \frac{1}{2} \hat{a}^{t}\left(\bar{X}_{1}+\bar{X}_{2}\right) \\
& =\frac{1}{2}\left(\bar{X}_{1}-\bar{X}_{2}\right)^{t} S_{\text {pooled }}^{-1}\left(\bar{X}_{1}+\bar{X}_{2}\right)
\end{aligned}
$$

Otherwise, if

$$
\begin{aligned}
& \hat{Y}_{0}=\left(\bar{X}_{1}-\bar{X}_{2}\right)^{t} S_{\text {pooled }}^{-1} X_{0} \\
& <\frac{1}{2}\left(\bar{X}_{1}-\bar{X}_{2}\right)^{t} S_{\text {pooled }}^{-1}\left(\bar{X}_{1}+\bar{X}_{2}\right)
\end{aligned}
$$

then allocate $X_{0}$ to population 2 .

where, $\bar{X}_{1}$ and $\bar{X}_{2}$ are the mean vector of the groups, $\hat{a}^{t}$ is the discriminant coefficient and $S_{\text {pooled }}^{-1}$ is the pooled standard deviation for two groups under comparison.

\section{Results and Discussion}

Descriptive analysis showed that the mean value in August month for Burdwan and Nadia districts is 3.59 
$\mathrm{m}$ and $2.93 \mathrm{~m}$ (Table 1), respectively, which is low compared to the rest of the months of the present study, which in turn mean that in August month the water table is high which may be mainly due to high rain fall in the season. Whereas the highest mean value is found in May as $6.58 \mathrm{~m}$ and $4.87 \mathrm{~m}$ (Table 1), respectively, which mean the low level of water table found in May month among the periods under investigation, which may be due to removal of water for irrigation purpose, more water absorption by plants particularly deep rooted plants and other water evolved activates. The average variation is less in case of Nadia district as compared to Burdwan district. Among the season, fluctuation is high in the month of May with standard deviation of $4.3 \mathrm{~m}$ and was least in case of November with standard deviation of 3.17 in Burdwan (Table 1). While in case of Nadia more variation was found in the month of August. Skewness is positive in all the months in both the districts except August month for Nadia, it showed negative skewness which might experienced a high changes in the later part of period under study. Similarly, all kurtic values were found to be positive except for the months of August and November at Nadia, which exhibited the negative kurtic values which might have experienced a steady changes. The negative growth rate in case of Burdwan for all the months expect for January may be due to implementation of ground water recycling/recharging programs like constructions of water cannels, rain water harvesting techniques, improved irrigation methods in recent years and also may be due to comparatively high rainfall by $9 \%$ in 2013 as that of average of period 2005-2012 [6], under study. But in case of Nadia district, the growth rate is positive for all the months, which clearly reflects that either withdrawal of groundwater is increasing year to year and recharging of groundwater is getting worse year to year or both.
The result of regression with dummy variable is framed in Table 2. The results indicate that in both districts ground water level improved significantly in the month of August and November. But in case of May month coefficient is positive which signifies that groundwater level is depleting in May month year to year.

Complete linkage clustering is carried out to identify and to group the sites. Three Clusters were obtained in both Burdwan and Nadia districts and are shown in the Table 3 and Table 4, respectively, and their respective dendrograms are given in Figs.1 and 2, respectively. Comparatively more similarity was observed between the cluster 1 and cluster 2 with a least distance of 7.528 in case of Burdwan and it is between clusters 2 and 3 in Nadia with a distance of 2.564 (Table 5).

For the three different clusters formed in both the district, one way ANOVA was carried out to verify the hypothesis that various clusters were exhibiting different season wise groundwater levels and results are presented in Table 6. Table 6 indicates that in both

Table 1 Descriptive statistics.

\begin{tabular}{lllll}
\hline Burdwan & & & & \\
\hline January & May & August & November \\
\hline Mean & 4.95 & 6.58 & 3.59 & 4.01 \\
Standard deviation & 3.78 & 4.30 & 3.71 & 3.17 \\
Kurtosis & 2.94 & 1.03 & 3.94 & 5.72 \\
Skewness & 1.80 & 1.34 & 2.12 & 2.27 \\
Minimum & 0.75 & 1.63 & 0.51 & 1.05 \\
Maximum & 17.90 & 19.55 & 16.23 & 16.97 \\
SGR\% & 1.98 & -1.51 & -2.37 & -3.35 \\
\hline Nadia & & & & \\
\hline Mean & 3.80 & 4.88 & 2.93 & 3.29 \\
Median & 3.83 & 4.89 & 2.80 & 3.32 \\
Standard deviation & 0.94 & 0.89 & 1.09 & 0.89 \\
Kurtosis & 0.10 & 0.37 & -0.86 & -0.69 \\
Skewness & 0.65 & 0.41 & -0.003 & 0.19 \\
Minimum & 2.45 & 3.28 & 1.13 & 1.85 \\
Maximum & 5.98 & 6.83 & 4.92 & 5.00 \\
SGR\% & 1.43 & 1.52 & 0.89 & 0.26 \\
\hline
\end{tabular}

Table 2 Model summary of trend model fitted.

\begin{tabular}{llll}
\hline District & Model & Significance & RMSE \\
\hline Burdwan & $Y=4.66+1.72 D_{2}-1.61 D_{3}-1.16 D_{4}$ & 0.00 & 0.773 \\
Nadia & $Y=4.25+1.23 D_{2}-0.98 D_{3}-0.55 D_{4}$ & 0.736 & 0.542 \\
\hline
\end{tabular}



sites in Nadia and Burdwan districts of West Bengal

Table 3 Clusters of 50 sites in Burdwan district.

\begin{tabular}{lllll}
\hline Cluster-1 & & & Cluster-2 & Cluster-3 \\
\hline No. of sites:36 & & No. of sites: 8 & No. of sites: 6 \\
\hline Ajhapur (1) & Dainhat (15) & Kultora (34) & Bandebaz (7) & Damodarpur (18) \\
Amira (2) & Dakshin Khanda (16) & Metedanga (37) & Bowaichandi TW (12) & Kaity (25) \\
Andal (3) & Dakshin Radhakantapur (17) & Mondalpur (38) & Deshbandhunagar (19) & Khalipur (31) \\
Asansol (4) & Domohani (21) & Neamatpur (39) & Dobrana (20) & Koichor (33) \\
Ausgram (5) & Durgapurbarage (22) & Orgram (40) & Kasba (29) & Mahadhabdihi SWID \\
Bamunpara (6) & Ethora (23) & Pandabeswar (41) & Sagrai PZ SWID (45) & Maladanga (36) \\
Barakar (8) & Gourandih (24) & Piala (42) & Samudragargh (47) & \\
Barddhaman (9) & Kalla (26) & Raniganj (43) & Sanko (48) & \\
Basudha (10) & Kalyaneswari (27) & Rupnarainpur (44) & & \\
Bhiringi (11) & Kanksa (28) & Salanpur (46) & & \\
Bogra (12) & Katwa Town (30) & Silampur (49) & & \\
Chittaranjan (14) & Khejurhati (32) & Singarkone (50) & & \\
\hline
\end{tabular}

Table 4 Clusters of 19 sites in Nadia district.

\begin{tabular}{llll}
\hline Cluster-1 & Cluster-2 & & Cluster-3 \\
\hline No. of Site: 4 & No. of site: 9 & & No. of Site: 6 \\
\hline Badkulla (1) & Baganchra (5) & Katwa Ghat (9) & Debagram Pz (14) \\
Bahadurpur (2) & Bhajan Ghat (6) & Nabadwip town (10) & Dignagar (15) \\
Banpur Pz (3) & Karimpur (7) & Nokari (11) & Gajna (16) \\
Narayanpur (4) & Karuigachhi (8) & Pairadanga (12) & Mayapur (17) \\
& & Uttar Kechuadanga (13) & Nabadwip Ghat (18) \\
& & & Palassey (19) \\
\hline
\end{tabular}

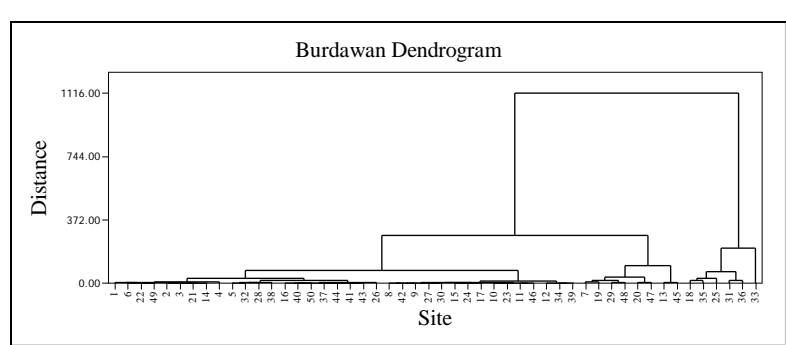

Fig. 1 Dendrogram showing the different Cluster of villages in Burdwan district.

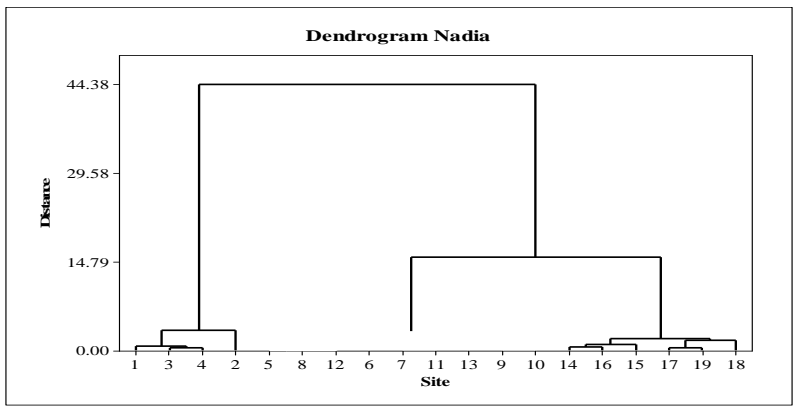

Fig. 2 Dendrogram showing the different Cluster of villages in Nadia district.

the districts, clusters formed are significantly different in all the seasons under study, which once again proves the correctness of classification.
In case of Burdwan, in all the months, sites falling in cluster-1 is having significantly high groundwater level as compared to other sites falling in other two remaining clusters. Also cluster-2 is significantly superior than cluseter-3. Similar results is also observed in case of Nadia district. Sites falling in cluster-3 are having superiorly high groundwater level in all the months than the remaining two clusters (Table 7).

Fisher's discriminant analysis helps us in assessing

Table 5 Distance between cluster formed in Burdwan and Nadia.

\begin{tabular}{llll}
\hline Burdwan & & & \\
\hline & Cluster1 & Cluster2 & Cluster3 \\
Cluster1 & 0.00 & 7.52 & 20.30 \\
Cluster2 & 7.52 & 0.00 & 12.83 \\
Cluster3 & 20.30 & 12.83 & 0.00 \\
\hline Nadia & & & \\
\hline & Cluster1 & Cluster2 & Cluster3 \\
Cluster1 & 0.00 & 2.56 & 4.83 \\
Cluster2 & 2.56 & 0.00 & 2.31 \\
Cluster3 & 4.83 & 2.31 & 0.00 \\
\hline
\end{tabular}


the important season which are contributing significantly towards group discriminations. It also helps in identifying the particular group for a given element. In this section, our endeavor is to identify the contribution of four seasons i.e., January, May, August and November in three clusters formed (in both Burdwan and Nadia), so that given any site one can identify its particular group where it should belong.

Based on the $\mathrm{D}^{2}$ value of each and every characters in group, discrimination are ranked, highest $\mathrm{D}^{2}$ is ranked one and the lowest one is ranked as 4 and from Table 8, for Burdwan district one can see that the maximum value of $\mathrm{D}^{2}$ is obtained in discriminating
Table 6 Depth of ground water table $(\mathrm{m})$ in different cluster of Burdwan and Nadia district.

\begin{tabular}{lllll}
\hline Burdwan district & & & & \\
\hline Cluster & January & May & August & November \\
Cluster1 & 3.066 & 4.550 & 1.792 & 2.493 \\
Cluster2 & 7.014 & 9.020 & 5.075 & 5.706 \\
Cluster3 & 13.508 & 15.518 & 12.402 & 10.875 \\
F Value & 142.410 & 68.820 & 192.460 & 87.040 \\
Significance level & 0.000 & 0.000 & 0.000 & 0.000 \\
\hline Nadia district & & & & \\
\hline Cluster1 & 5.255 & 6.186 & 4.352 & 4.578 \\
Cluster2 & 3.795 & 4.908 & 3.158 & 3.401 \\
Cluster3 & 2.851 & 3.960 & 1.645 & 2.278 \\
F Value & 55.305 & 40.869 & 51.150 & 70.747 \\
Significance level & 0.000 & 0.000 & 0.000 & 0.000 \\
\hline
\end{tabular}

Table 7 Multiple comparison for different season for formed cluster.

\begin{tabular}{|c|c|c|c|c|c|c|c|c|c|c|c|c|c|}
\hline \multicolumn{14}{|c|}{ Burdwan District } \\
\hline \multicolumn{2}{|c|}{ Treatment } & \multicolumn{3}{|c|}{ January } & \multicolumn{3}{|c|}{ May } & \multicolumn{3}{|c|}{ August } & \multicolumn{3}{|c|}{ November } \\
\hline (I) & $(\mathrm{J})$ & MD (I-J) & SE & Sig. & MD (I-J) & SE & Sig. & MD (I-J) & SE & Sig. & MD (I-J) & $\mathrm{SE}$ & Sig. \\
\hline \multirow[t]{2}{*}{$\mathrm{C} 1$} & $\mathrm{C} 2$ & $-3.947^{*}$ & 0.568 & 0 & $-4.470^{*}$ & 0.866 & 0 & $-3.284^{*}$ & 0.488 & 0 & $-3.214^{*}$ & 0.584 & 0 \\
\hline & $\mathrm{C} 3$ & $-10.440^{*}$ & 0.641 & 0 & $-10.965^{*}$ & 0.977 & 0 & $-10.608^{*}$ & 0.55 & 0 & $-8.381^{*}$ & 0.659 & 0 \\
\hline \multirow[t]{2}{*}{$\mathrm{C} 2$} & $\mathrm{C} 1$ & $3.947^{*}$ & 0.568 & 0 & $4.470^{*}$ & 0.866 & 0 & $3.284^{*}$ & 0.488 & 0 & $3.214^{*}$ & 0.584 & 0 \\
\hline & $\mathrm{C} 3$ & $-6.492^{*}$ & 0.785 & 0 & $-6.495^{*}$ & 1.196 & 0 & $-7.323^{*}$ & 0.674 & 0 & $-5.167^{*}$ & 0.807 & 0 \\
\hline \multirow[t]{2}{*}{ C3 } & C1 & $10.440^{*}$ & 0.641 & 0 & $10.965^{*}$ & 0.977 & 0 & $10.608^{*}$ & 0.55 & 0 & $8.381^{*}$ & 0.659 & 0 \\
\hline & $\mathrm{C} 2$ & $6.492^{*}$ & 0.785 & 0 & $6.495^{*}$ & 1.196 & 0 & $7.323^{*}$ & 0.674 & 0 & $5.167^{*}$ & 0.807 & 0 \\
\hline \multicolumn{14}{|c|}{ Nadia District } \\
\hline \multirow[t]{2}{*}{ C1 } & C2 & $1.4591^{*}$ & 0.213 & 0 & $1.2785^{*}$ & 0.229 & 0 & $1.1940^{*}$ & 0.255 & 0 & $1.1764^{*}$ & 0.181 & 0 \\
\hline & C3 & $2.4036^{*}$ & 0.229 & 0 & $2.2260^{*}$ & 0.246 & 0 & $2.7076^{*}$ & 0.274 & 0 & $2.2996^{*}$ & 0.195 & 0 \\
\hline \multirow[t]{2}{*}{$\mathrm{C} 2$} & $\mathrm{C} 1$ & $-1.4591^{*}$ & 0.213 & 0 & $-1.2785^{*}$ & 0.229 & 0 & $-1.1940^{*}$ & 0.255 & 0 & $-1.1764^{*}$ & 0.181 & 0 \\
\hline & C3 & $0.9445^{*}$ & 0.187 & 0 & $0.9475^{*}$ & 0.201 & 0 & $1.5136^{*}$ & 0.224 & 0 & $1.1232^{*}$ & 0.159 & 0 \\
\hline \multirow[t]{2}{*}{ C3 } & $\mathrm{C} 1$ & $-2.4036^{*}$ & 0.229 & 0 & $-2.2260^{*}$ & 0.246 & 0 & $-2.7076^{*}$ & 0.274 & 0 & $-2.2996^{*}$ & 0.195 & 0 \\
\hline & $\mathrm{C} 2$ & $-0.9445^{*}$ & 0.187 & 0 & $-0.9475^{*}$ & 0.201 & 0 & $-1.5136^{*}$ & 0.224 & 0 & $-1.1232^{*}$ & 0.159 & 0 \\
\hline
\end{tabular}

Table 8 Results of Discriminate analysis.

\begin{tabular}{llllll}
\hline & January & May & August & November & $\mathrm{D}^{2}$ \\
\hline Burdwan & & & & & \\
\hline C1 Vs C2 & 3 & 2 & 4 & 1 & 20.70 \\
C1 Vs C3 & 3 & 4 & 2 & 1 & 63.58 \\
C2 Vs C3 & 3 & 4 & 1 & 2 & 19.11 \\
\hline Nadia & & & & & \\
\hline C1 Vs C2 & 2 & 4 & 1 & 3 & 18.83 \\
C1 Vs C3 & 2 & 4 & 1 & 3 & 90.00 \\
C2 Vs C3 & 2 & 4 & 1 & 3 & 19.26 \\
\hline
\end{tabular}

cluster-1 with cluster-3 (63.58, Table 8), followed by cluster- 1 and cluster- 2 . It is found that none of the season's groundwater level could uniformly be taken as the best one in all groups' discrimination. GWL (ground water level) of December plays most contributing factor in discriminating cluster- 1 with cluster-2 as well cluster-3. Whereas GWL of August month in cluster-2 versus cluster-3. In case of Nadia District, GWL in August month can be taken as the best month for group discrimination followed by January. Maximum value of $\mathrm{D}^{2}$ is obtained in discriminating cluster-1 with cluster-3.

\section{Conclusions}

From the above study, it is clear that ground water table varies not only among the sites of each districts, but also among the sites. Ground water table depth 
also varies during different parts of the year. To have a meaningful and concrete ground water table maintenance strategy, different places could be grouped based on their characteristics. As such multivariate cluster analysis to group the places could be an option. Cluster analysis reflects that in spite of all these variations among the sites, these could be grouped under 3 groups. Taking care of the group characteristics of different clusters, definite corrective policy measures could be adopted to maintain and improve the ground water table depth. The method may also be applied in other areas to meet the challenge of groundwater depletion, particularly under changing climatic scenario.

\section{References}

[1] Swaminaryan, P. R., and Gupta, S. 2014. "Development of Geo-Visualized Information System for States of India Based on Rainfall Using ArcGIS.” International Journal of Recent and Innovation Trends in Computing and Communication 2 (7): 1894-6.

[2] Anon. 2014. "Indian Economic Survey 2013-14: Key Highlights.” KPMG Flash News 1.

[3] Anon, 2012. "Ground Water Year Book-India. Central Ground Water Board.” Ministry of water resources, Faridabad: GOI. 14.

[4] Rudra, K. 2013. "The Status of Water Resources in West Bengal.” Accessed December 12, 2014. http://www.indiawaterportal.org/articles.

[5] Anon, 2011. "State Action Plan on Climate Change." Government of West Bengal, GOI. 52.

[6] Anon. 2014. IMD, Pune. Assessed December 12, 2014. http://www.imd.gov.in/section/hydro/distrainfall. 